\title{
Erratum to: New Genes for Focal Epilepsies with Speech and Language Disorders
}

\author{
Samantha J. Turner ${ }^{1,2,6}$ • Angela T. Morgan ${ }^{1,2,3}$ • Eliane Roulet Perez ${ }^{4}$. \\ Ingrid E. Scheffer ${ }^{1,5,6}$
}

Published online: 23 June 2015

(C) Springer Science+Business Media New York 2015

\section{Erratum to: Curr Neurol Neurosci Rep (2015) 15:35}

DOI: $10.1007 / \mathbf{s} 11910-015-0554-0$

The original version of this article contained errors in Table 2. The column heading reading "No of seizures" should read "No seizures". The third entry under the column heading "Other" should read "Absence epilepsy" not "Absence of epilepsy". Lastly, in the last column, "panayiotopoulus syndrome" should read "Panayiotopoulus syndrome". References to "Table 1" on the fourth page should read "Table 2".

The online version of the original article can be found at http://dx.doi.org/ 10.1007/s11910-015-0554-0.

Ingrid E. Scheffer

scheffer@unimelb.edu.au

Samantha J. Turner

s.turner4@student.unimelb.edu.au

Angela T. Morgan

angela.morgan@mcri.edu.au

Eliane Roulet Perez

Eliane.Roulet-Perez@chuv.ch

1 Department of Paediatrics, The University of Melbourne, The Royal Children's Hospital, Parkville, Australia

2 Language and Literacy Group, Murdoch Childrens Research Institute, Parkville, Australia

3 Speech Pathology Department, The Royal Children's Hospital, Parkville, Australia

4 Paediatric Neurology and Neurorehabilitation Unit, Hospitalier Universitaire Vaudois, Lausanne, Switzerland

5 Florey Institute of Neuroscience and Mental Health, Melbourne, Australia

6 Epilepsy Research Centre, Department of Medicine, University of Melbourne, Austin Health, Melbourne, Australia 